\title{
Heterogeneous studies in pulping of wood: Modelling mass transfer of alkali
}

\author{
João P.F. Simão, Ana P.V. Egas, M. Graça Carvalho, \\ Cristina M.S.G. Baptista*, José Almiro A.M. Castro \\ CIEPQPF, Department of Chemical Engineering, University of Coimbra, P-3030 790 Coimbra, Portugal \\ Received 24 May 2007; received in revised form 11 September 2007; accepted 12 September 2007
}

\begin{abstract}
In this paper a heterogeneous lumped parameter model is proposed to describe the mass transfer of effective alkali during the kraft pulping of wood. This model, based on the spatial mean of the concentration profile of effective alkali along the chip thickness, enables the estimation of the effective diffusion coefficient that characterizes the internal resistance to mass transfer and the contribution of the external resistance to mass transfer which has often been neglected.

The experimental data that support this study comprise measurements of alkali concentration in the liquid phases, both inside and outside the chips. The kraft pulping of Eucalyptus globulus was carried out using broad range of temperature (80-165 $\left.{ }^{\circ} \mathrm{C}\right)$ and effective alkali charge (10-45 $\mathrm{g}$ $\left.\mathrm{Na}_{2} \mathrm{O}(100 \mathrm{~g} \text { odw })^{-1}\right)$.

The model describes the effective alkali concentration profiles in the free liquor along the cooking with accuracy. The effective diffusion coefficient has been expressed by an Arrhenius-type equation and the estimated value of the activation energy for diffusion $\left(E_{\mathrm{a}}=20.7 \mathrm{~kJ} \mathrm{~mol}^{-1}\right)$ is in agreement with previous studies. The contribution of the external resistance to the overall mass transfer resistance showed to be significant and to increase with both temperature and effective alkali charge at industrial operation conditions. This result confirms the relevance of building a model that takes into account the heterogeneous nature of the kraft pulping of E. globulus.
\end{abstract}

(C) 2007 Elsevier B.V. All rights reserved.

Keywords: Heterogeneous system; Mass transfer model; Effective diffusion coefficient; Kraft pulping; Eucalyptus globulus

\section{Introduction}

Mass transfer of inorganic chemicals plays an important role in the overall rate of wood pulping due to the strong heterogeneous nature of the process. The main reactions that take place during this process occur between lignin and carbohydrates in the solid matrix of the wood and the inorganic reactants dissolved in the liquid entrapped within its porous structure. Therefore, to really improve the understanding of the kraft pulping process and to enable realistic optimization studies of the operation of industrial reactors [1] it is essential to quantify the rate of mass transfer of alkali from the bulk of the liquor to the inside of the chips.

\footnotetext{
* Corresponding author. Tel.: +351 239 798700/738; fax: +351 239798703 . E-mail address: cristina@eq.uc.pt (C.M.S.G. Baptista).

Deceased.
}

In the history of kraft pulping research, the heterogeneous nature of the process has been neglected to a large extent. Due to experimental limitations, the available data on the alkali concentration in the liquor inside the chips are very scarce, when compared to the amount of data on the bulk liquor. There are very few studies on this subject [2-5] and these only allow to roughly estimate the concentration of alkali in the entrapped liquor. Moreover, none of these studies were performed with the purpose of building a kinetic model for pulping based on the measurement of alkali concentration in the entrapped liquor. As a consequence, in most of the models available, the rates of reaction of lignin and of carbohydrates in the wood matrix are related to the composition of the bulk liquor surrounding the chips, which is of little physical significance for the development of real heterogeneous kinetic models.

Some theoretical models have been proposed to describe the kraft pulping process, in which both chemical reaction and mass transfer were considered [6-8]. However, the great detail that characterizes such models is not backed up by consistent and 


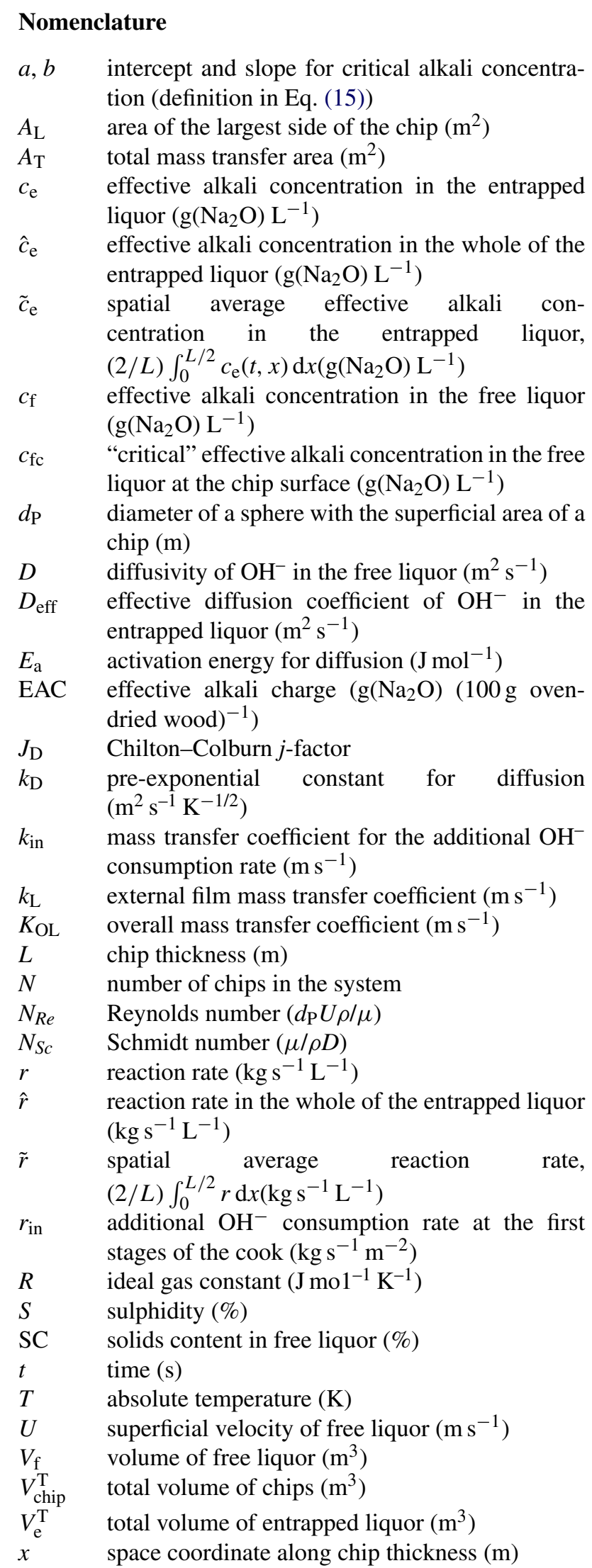

$a, b \quad$ intercept and slope for critical alkali concentration (definition in Eq. (15))

$A_{\mathrm{L}} \quad$ area of the largest side of the chip $\left(\mathrm{m}^{2}\right)$

$A_{\mathrm{T}} \quad$ total mass transfer area $\left(\mathrm{m}^{2}\right)$

$c_{\mathrm{e}} \quad$ effective alkali concentration in the entrapped liquor $\left(\mathrm{g}\left(\mathrm{Na}_{2} \mathrm{O}\right) \mathrm{L}^{-1}\right)$

$\hat{c}_{\mathrm{e}} \quad$ effective alkali concentration in the whole of the entrapped liquor $\left(\mathrm{g}\left(\mathrm{Na}_{2} \mathrm{O}\right) \mathrm{L}^{-1}\right)$

$\tilde{c}_{\mathrm{e}}$ spatial average effective alkali concentration in the entrapped liquor, $(2 / L) \int_{0}^{L / 2} c_{\mathrm{e}}(t, x) \mathrm{d} x\left(\mathrm{~g}\left(\mathrm{Na}_{2} \mathrm{O}\right) \mathrm{L}^{-1}\right)$

$c_{\mathrm{f}} \quad$ effective alkali concentration in the free liquor $\left(\mathrm{g}\left(\mathrm{Na}_{2} \mathrm{O}\right) \mathrm{L}^{-1}\right)$

$c_{\mathrm{fc}} \quad$ "critical" effective alkali concentration in the free liquor at the chip surface $\left(\mathrm{g}\left(\mathrm{Na}_{2} \mathrm{O}\right) \mathrm{L}^{-1}\right)$

$d_{\mathrm{P}} \quad$ diameter of a sphere with the superficial area of a chip (m)

$D \quad$ diffusivity of $\mathrm{OH}^{-}$in the free liquor $\left(\mathrm{m}^{2} \mathrm{~s}^{-1}\right)$

$D_{\text {eff }}$ effective diffusion coefficient of $\mathrm{OH}^{-}$in the entrapped liquor $\left(\mathrm{m}^{2} \mathrm{~s}^{-1}\right)$

$E_{\mathrm{a}} \quad$ activation energy for diffusion $\left(\mathrm{J} \mathrm{mol}^{-1}\right)$

EAC effective alkali charge $\left(\mathrm{g}\left(\mathrm{Na}_{2} \mathrm{O}\right)\right.$ (100 $\mathrm{g}$ ovendried wood) ${ }^{-1}$ )

$J_{\mathrm{D}} \quad$ Chilton-Colburn $j$-factor

$k_{\mathrm{D}}$ pre-exponential constant for diffusion $\left(\mathrm{m}^{2} \mathrm{~s}^{-1} \mathrm{~K}^{-1 / 2}\right)$

$k_{\text {in }} \quad$ mass transfer coefficient for the additional $\mathrm{OH}^{-}$ consumption rate $\left(\mathrm{m} \mathrm{s}^{-1}\right)$

$k_{\mathrm{L}} \quad$ external film mass transfer coefficient $\left(\mathrm{m} \mathrm{s}^{-1}\right)$

$K_{\mathrm{OL}} \quad$ overall mass transfer coefficient $\left(\mathrm{m} \mathrm{s}^{-1}\right)$

$L \quad$ chip thickness (m)

$N \quad$ number of chips in the system

$N_{R e} \quad$ Reynolds number $\left(d_{\mathrm{P}} U \rho / \mu\right)$

$N_{S c} \quad$ Schmidt number $(\mu / \rho D)$

$r \quad$ reaction rate $\left(\mathrm{kg} \mathrm{s}^{-1} \mathrm{~L}^{-1}\right)$

$\hat{r}$ reaction rate in the whole of the entrapped liquor $\left(\mathrm{kg} \mathrm{s}^{-1} \mathrm{~L}^{-1}\right)$

$\tilde{r}$ spatial average reaction rate, $(2 / L) \int_{0}^{L / 2} r \mathrm{~d} x\left(\mathrm{~kg} \mathrm{~s}^{-1} \mathrm{~L}^{-1}\right)$

$r_{\text {in }}$ additional $\mathrm{OH}^{-}$consumption rate at the first stages of the cook $\left(\mathrm{kg} \mathrm{s}^{-1} \mathrm{~m}^{-2}\right)$

$R \quad$ ideal gas constant $\left(\mathrm{J} \mathrm{mol}^{-1} \mathrm{~K}^{-1}\right)$

$S \quad$ sulphidity (\%)

$\mathrm{SC} \quad$ solids content in free liquor (\%)

$t \quad$ time (s)

$T \quad$ absolute temperature (K)

$U \quad$ superficial velocity of free liquor $\left(\mathrm{m} \mathrm{s}^{-1}\right)$

$V_{\mathrm{f}} \quad$ volume of free liquor $\left(\mathrm{m}^{3}\right)$

$V_{\text {chip }}^{\mathrm{T}} \quad$ total volume of chips $\left(\mathrm{m}^{3}\right)$

$V_{\mathrm{e}}^{\mathrm{T}} \quad$ total volume of entrapped liquor $\left(\mathrm{m}^{3}\right)$

$x \quad$ space coordinate along chip thickness (m)
Greek letters
$\beta_{1}, \beta_{2}, \beta_{3}$ model parameters
$\varepsilon \quad$ chip porosity
$\varepsilon_{\mathrm{b}} \quad$ bulk porosity
$\mu \quad$ viscosity of free liquor (Pa s)
$\rho \quad$ density of free liquor $\left(\mathrm{kg} \mathrm{m}^{-3}\right)$

extensive pulping data. These global models have never been validated in practice, because there is not enough reliable experimental information relating entrapped liquor concentration to chemical reaction rates within the solid matrix.

Agarwal et al. [9] developed a diffusion model for alkali using a pulping model that included both physical and chemical phenomena. The mass transfer model was built in two steps. First the kinetic models for chemical reaction were obtained from cooking experiments carried out with thin chips and, based on the assumption of no internal or external mass transfer resistances, the kinetic parameters obtained were then used to estimate the alkali diffusion model, at this stage using pulping experiments with thick chips. However, with such a strategy, some assumptions had to be made thus reducing the accuracy of the model. One assumption refers to not accounting for the mass transfer limitations of alkali in thin chips. This implies that the concentration profiles of alkali in both the free and the entrapped liquors are the same along the cooking experiment, which is not confirmed experimentally, as shown by Egas et al. [10]. Moreover, the reactions between alkali and the wood components other than lignin and carbohydrates are neglected, thus leading to unrealistic alkali profiles during cooking.

More recently, a significant effort to estimate the diffusion parameters during wood impregnation was made by Kazi et al. [11]. In their experimental programme the authors impregnated wood cylinders with a sodium hydroxide solution at different impregnation pressures and temperatures. The sodium concentration profiles were then measured in the axial and radial directions, using a very elaborate procedure for sample preparation and the SEM technique for sodium quantification. However, in the model proposed for impregnation, it is assumed that no chemical reactions occur between alkali and wood components and that sodium does not adsorb on the solid matrix. These phenomena may not be always negligible $[10,12,13]$ and this may influence the diffusion parameters calculated. Moreover, the low range of temperatures used in the experimental studies $\left(25-100^{\circ} \mathrm{C}\right)$ does not enable using their diffusion model in normal pulping conditions.

This paper proposes a model for the mass transfer of alkali from the bulk liquor to the inside of the wood chips that is based on data on the composition of both free and entrapped liquors. The pulping experiments followed the methodology proposed by Egas et al. [10] and the relevance of the information gathered on the entrapped liquor has been confirmed by Simão et al. $[14,15]$. This mass transfer model relies on a lumped parameter approximation, in which the concentration profile of alkali inside the chip is represented by its spatial average concentration. 
Table 1

Operating conditions used in the experimental study

\begin{tabular}{|c|c|c|c|c|}
\hline $\begin{array}{l}\text { Initial effective alkali charge } \\
\left(\mathrm{g} \mathrm{Na}_{2} \mathrm{O}\left(100 \mathrm{~g} \mathrm{odw}^{-1}\right)\right.\end{array}$ & $\begin{array}{l}\text { Initial } \\
\text { sulphidity }(\%)\end{array}$ & $\begin{array}{l}\text { Cooking } \\
\text { temperature }\left({ }^{\circ} \mathrm{C}\right)\end{array}$ & $\begin{array}{l}\text { Time-to-temperature } \\
\text { (min) }\end{array}$ & $\begin{array}{l}\text { Number of pulping experiments/number } \\
\text { of independent samples }\end{array}$ \\
\hline 15 & 30 & 80 & & $2 / 12$ \\
\hline 15 & 30 & 110 & 0 & $3 / 18$ \\
\hline 15 & 30 & 125 & 20 & $3 / 18$ \\
\hline 15 & 30 & 140 & 40 & $6 / 36$ \\
\hline 15 & 30 & 150 & 45 & $2 / 12$ \\
\hline 15 & 30 & 165 & 50 & $5 / 30$ \\
\hline 20 & 30 & 140 & 40 & $2 / 12$ \\
\hline 25 & 30 & 140 & 40 & $2 / 12$ \\
\hline 45 & 30 & 140 & 40 & $2 / 12$ \\
\hline 10 & 30 & 165 & 50 & $2 / 12$ \\
\hline 20 & 30 & 165 & 50 & $2 / 12$ \\
\hline 30 & 30 & 165 & 50 & $2 / 12$ \\
\hline 15 & 15 & 165 & 50 & $2 / 12$ \\
\hline 15 & 45 & 165 & 50 & $2 / 12$ \\
\hline 15 & 60 & 165 & 50 & $2 / 12$ \\
\hline 15 & 75 & 165 & 50 & $2 / 12$ \\
\hline
\end{tabular}

Although assuming the heterogeneous nature of the process, this lumped parameter approach can be easily used and, above all, it has been validated by a large number of pulping experiments. It also incorporates the two main mass transfer resistances: an internal resistance, by diffusion, inside the chips, and an external resistance in the surrounding film of liquid involving the chip. One additional advantage of this method, with regard to others, is that it does not require any simplifying assumption on the chemical reactions, as the alkali concentrations in both the bulk and the entrapped liquors are measured along time.

\section{Experimental}

The experimental procedure adopted here has already been described in detail by Egas et al. [10]. Handmade Eucalyptus globulus chips (size: $30 \mathrm{~mm} \times 30 \mathrm{~mm} \times 6 \mathrm{~mm}$ ) were cooked in a six-vessel computer controlled batch-digester system described by Romanenko and Castro [16]. Each experiment consisted in a set of six simultaneous cooks in the same reaction conditions, but with different pulping times. Since the chips were fully pre-impregnated with water at the beginning of the cook, the penetration mechanism is considered negligible.

The initial effective alkali concentration, the initial sulphidity and the temperature profile varied among experiments, while the initial liquor-to-wood ratio remained $8 \mathrm{~L} / \mathrm{kg}$. The standard sulphidity was set to $30 \%$. Table 1 summarizes the conditions used in the experiments.

In each experiment, both the free and the entrapped liquors were analyzed for sulphide and active alkali concentrations, as well as dissolved solids and lignin. Wood samples were also characterized.

Fig. 1 shows typical effective alkali concentration profiles in both free and entrapped liquors, for an experiment carried out at a target temperature of $140{ }^{\circ} \mathrm{C}$. The amount of alkali that disappears from the liquor surrounding the chips (free liquor), as a result of both mass transfer and chemical reaction, can be related to the alkali concentration gradient between the two liquid phases, independently of the chemical reactions that take place in the wood matrix. However, as Fig. 1 illustrates, at the beginning of the cooking experiments there is a fast and sharp decrease in the concentration of alkali in the free liquor, which is not followed by a corresponding increase in the concentration of alkali in the entrapped liquor. This could be explained by the occurrence of fast chemical reactions between alkali and some constituents of wood, namely acetyl groups and extractives, which can be considered to dissolve in the free liquor in the first $5-8 \mathrm{~min}$ of the cook [17]. Therefore, the mass balance to the free liquor will take into account these early reactions in an additional term in the following model development.

\section{Model development}

In the lumped parameter approach adopted here for the modelling of mass transfer, one uses the spatial average of the alkali concentration profile along the chip thickness, $\tilde{c}_{\mathrm{e}}$ (see Fig. 2),

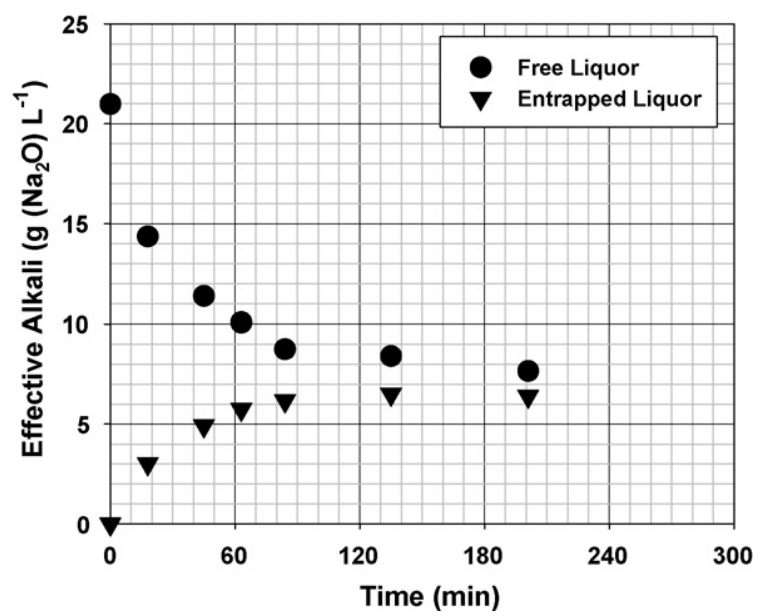

Fig. 1. Effective alkali concentration profiles in the bulk and entrapped liquor for a pulping experiment $\left(T=140^{\circ} \mathrm{C}, \mathrm{EAC}=15 \mathrm{~g} \mathrm{Na}_{2} \mathrm{O}(100 \mathrm{~g} \mathrm{odw})^{-1}, S=30 \%\right)$. 


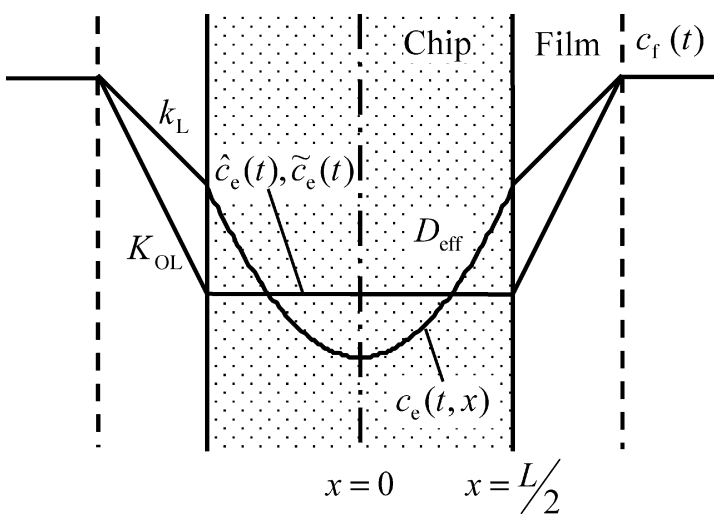

Fig. 2. Effective alkali profile across the chip and its space average equivalent.

that allows us to use the available data on the alkali concentration in the whole entrapped liquor. With this macroscopic strategy the total resistance to mass transfer is lumped into the external film as an overall mass transfer coefficient $\left(K_{\mathrm{OL}}\right)$, relating the concentration in the free liquor to the mean concentration in the liquid inside the chip. This is illustrated in Fig. 2, where this resistance is greater than the film resistance alone in the microscopic model, because it already embodies the internal mass transfer resistance. The experimental data available to build the model are the average alkali concentrations in the entrapped and free liquors which enable the estimation of the overall mass transfer coefficient. This can, then, be related to the external film mass transfer coefficient $\left(k_{\mathrm{L}}\right)$ and to the effective diffusion coefficient inside the chip ( $D_{\text {eff }}$ ).

In order to build the mass transfer model for this system the following assumptions have been made:

- The bulk phase is homogeneous and well mixed.

- Heat transfer limitations are considered negligible, which means that there are no temperature gradients between the free and entrapped liquors; moreover, the temperature is uniform in both the liquid and solid phases.

- The chip has slab geometry and its critical dimension is the thickness.

- Convection inside the chip is considered negligible.

- The activity coefficient for $\mathrm{OH}^{-}$is constant inside and outside the chip.

- The effective diffusion coefficient is constant inside the chip.

The macroscopic mass balances to the effective alkali in both the free and the entrapped liquors lead to the following equations:

$\frac{\mathrm{d}\left(V_{\mathrm{f}} c_{\mathrm{f}}\right)}{\mathrm{d} t}=-K_{\mathrm{OL}} A_{\mathrm{T}}\left[c_{\mathrm{f}}(t)-\hat{c}_{\mathrm{e}}(t)\right]$

$\frac{\mathrm{d}\left(V_{\mathrm{e}}^{\mathrm{T}} \hat{c}_{\mathrm{e}}\right)}{\mathrm{d} t}=K_{\mathrm{OL}} A_{\mathrm{T}}\left[c_{\mathrm{f}}(t)-\hat{c}_{\mathrm{e}}(t)\right]-\hat{r} V_{\text {chip }}^{\mathrm{T}}$

where $V_{\mathrm{f}}$ and $V_{\mathrm{e}}^{\mathrm{T}}$ are the total volumes of free and entrapped liquors in the system, $c_{\mathrm{f}}(t)$ and $\hat{c}_{\mathrm{e}}(t)$ the effective alkali concentrations in the free liquor and in the whole of the entrapped liquor, $V_{\text {chip }}^{\mathrm{T}}$ the total volume of chips, $\hat{r}$ the reaction rate in the whole of the entrapped liquor and $A_{\mathrm{T}}$ is the total interface mass transfer area.

On the other hand, a microscopic mass balance to the effective alkali concentration in the entrapped liquor is described by the following equation:

$$
\frac{\partial\left(\varepsilon c_{\mathrm{e}}\right)}{\partial t}=D_{\text {eff }}\left(\frac{\partial^{2} c_{\mathrm{e}}}{\partial x^{2}}\right)-r
$$

with the boundary conditions:

$x=\left.0 \Rightarrow\left(\frac{\partial c_{\mathrm{e}}}{\partial x}\right)\right|_{x=0}=0$

$x=\left.\frac{L}{2} \Rightarrow D_{\text {eff }}\left(\frac{\partial c_{\mathrm{e}}}{\partial x}\right)\right|_{x=L / 2}=k_{\mathrm{L}}\left[c_{\mathrm{f}}(t)-c_{\mathrm{e}}\left(t, \frac{L}{2}\right)\right]$

and the initial conditions

$t=0 \Rightarrow\left\{\begin{array}{l}c_{\mathrm{e}}(0, x)=0 \\ c_{\mathrm{f}}(0)=c_{\mathrm{f}}^{0}\end{array}\right.$

where $c_{\mathrm{e}}(t, x)$ is the local effective alkali concentration in the entrapped liquor, $\varepsilon$ the chip porosity, $r$ the local reaction rate and $L$ is the chip thickness.

By using spatial averages for the alkali concentration in the entrapped liquor, $\tilde{c}_{\mathrm{e}}(t)$, and for the average reaction rate, $\tilde{r}$, in Eqs. (3)-(5) and assuming that the spatial effective alkali concentration profile in the entrapped liquor is symmetric at $x=0$ and described by a second order polynomial, one obtains the following lumped model expressed in terms of $\tilde{c}_{\mathrm{e}}(t)$ :

$\frac{\mathrm{d}\left(\varepsilon \tilde{c}_{\mathrm{e}}\right)}{\mathrm{d} t}=\frac{12 D_{\text {eff }} k_{\mathrm{L}}}{L\left(6 D_{\text {eff }}+L k_{\mathrm{L}}\right)}\left[c_{\mathrm{f}}(t)-\tilde{c}_{\mathrm{e}}(t)\right]-\tilde{r}$

Since the volume of the entrapped liquid is given by $V_{\mathrm{e}}^{\mathrm{T}}=$ $\varepsilon L A_{\mathrm{L}} N$ and the total surface area for mass transfer is $A_{\mathrm{T}}=$ $2 A_{\mathrm{L}} N$, where $A_{\mathrm{L}}$ is the area of the largest side of the chip and $N$ is the number of chips in the system, one can multiply Eq. (7) by $V_{\text {chip }}^{\mathrm{T}}=L A_{\mathrm{L}} N$ and thus:

$\frac{\mathrm{d}\left(V_{\mathrm{e}}^{\mathrm{T}} \tilde{c}_{\mathrm{e}}\right)}{\mathrm{d} t}=\frac{6 D_{\text {eff }} k_{\mathrm{L}}}{6 D_{\text {eff }}+L k_{\mathrm{L}}} A_{\mathrm{T}}\left[c_{\mathrm{f}}(t)-\tilde{c}_{\mathrm{e}}(t)\right]-\tilde{r} V_{\text {chip }}^{\mathrm{T}}$

Since $\tilde{c}_{\mathrm{e}}$ in Eq. (8) and $\hat{c}_{\mathrm{e}}$ in Eq. (2) have the same meaning, one can state that

$\frac{1}{K_{\mathrm{OL}}}=\frac{1}{k_{\mathrm{L}}}+\frac{L}{6 D_{\mathrm{eff}}}$

The effective diffusion coefficient is often considered to depend on temperature, following an Arrhenius-type equation $[2,3,17]$ :

$D_{\text {eff }}=\varepsilon k_{\mathrm{D}} \sqrt{T} \mathrm{e}^{-E_{\mathrm{a}} / R T}$

where $k_{\mathrm{D}}$ is a pre-exponential constant, $T$ the absolute temperature, $E_{\mathrm{a}}$ an activation energy for diffusion and $R$ is the ideal gas constant. The chip porosity $(\varepsilon)$ is included here because in this non-catalytic liquid-solid reaction system, it depends on the extent of the reaction and therefore it is not constant during the process. 
According to Dwidevi and Upadhyay [18] the external film mass transfer coefficient can be determined using the following correlation for liquid-solid systems:

$k_{\mathrm{L}}=\frac{J_{\mathrm{D}} U}{N_{S c}^{2 / 3}}$

$J_{\mathrm{D}}=\frac{1}{\varepsilon_{\mathrm{b}}}\left(\frac{0.765}{N_{R e}^{0.82}}+\frac{0.365}{N_{R e}^{0.386}}\right)$

where $J_{\mathrm{D}}$ is the Chilton-Colburn $j$-factor for mass transfer, $U$ the superficial velocity of the free liquor, $\varepsilon_{\mathrm{b}}$ the bulk porosity and $N_{S c}$ and $N_{R e}$ are the Schmidt and Reynolds numbers. The superficial velocity was related to the average flow rate in the cooking experiments and the digesters cross-sectional area.

The viscosity of the liquor $(\mu)$ was determined as a function of the solids content (SC) and temperature (T), according to the correlation proposed by Gonçalves and Lobo [19]:

$\log \mu=-1.643-0.044 \mathrm{SC}+\frac{393+30 \mathrm{SC}}{T}$

Both the solids content and the temperature depend on the extent of the cook.

The diffusivity of $\mathrm{OH}^{-}$in the free liquor was corrected by viscosity and temperature using a modified Stokes-Einstein equation [20]:

$D=D_{0} \frac{\mu_{0}}{\mu} \frac{T}{T_{0}}$

where $D_{0}$ is the diffusivity of $\mathrm{OH}^{-}$in water $\left(2.12931 \times 10^{-9} \mathrm{~m}^{2} \mathrm{~s}^{-1},[21]\right), T_{0}$ is $298 \mathrm{~K}$ and $\mu_{0}$ is the viscosity of water at that temperature.

As it was previously mentioned, in order to account for the rapid consumption of effective alkali that occurs in the beginning of the cook, a term was added to the mass balance described by Eq. (1). This term is related to a "critical" alkali concentration, $c_{\mathrm{fc}}$, defined as the minimum alkali concentration up to which the contribution of these reactions is relevant. The preliminary tests showed that $c_{\mathrm{fc}}$ is a linear function of the initial alkali concentration in the free liquid, $c_{\mathrm{f}}^{0}$ :

$c_{\mathrm{fc}}=a+b c_{\mathrm{f}}^{0}$

This consumption term is given, at each instant, by the difference between the alkali concentration in the free liquid and the above-mentioned "critical" concentration, multiplied by a coefficient, $k_{\text {in }}$. In the range of temperatures used, this very fast consumption is assumed to be not dependent on temperature :

$r_{\text {in }}=k_{\text {in }}\left[c_{\mathrm{f}}(t)-c_{\mathrm{fc}}\right]$

This term is added to the mass balance in Eq. (1) until the alkali concentration in the free liquid equals the "critical" concentration. This strategy enables obtaining a good estimate of the flow of effective alkali that is transferred from the free to the entrapped liquor during the initial stages of the cooking:

$V_{\mathrm{f}}\left(\frac{\mathrm{d} c_{\mathrm{f}}}{\mathrm{d} t}\right)=-A_{\mathrm{T}}\left(K_{\mathrm{OL}}\left[c_{\mathrm{f}}(t)-\tilde{c}_{\mathrm{e}}(t)\right]+r_{\mathrm{in}}\right) \quad$ if $c_{\mathrm{f}}>c_{\mathrm{fc}}$
$V_{\mathrm{f}}\left(\frac{\mathrm{d} c_{\mathrm{f}}}{\mathrm{d} t}\right)=-A_{\mathrm{T}} K_{\mathrm{OL}}\left[c_{\mathrm{f}}(t)-\tilde{c}_{\mathrm{e}}(t)\right] \quad$ if $c_{\mathrm{f}} \leq c_{\mathrm{fc}}$

\section{Results and discussion}

The cooking experiments carried out in the digesters system, at temperatures in the range $80-165^{\circ} \mathrm{C}$ and initial effective alkali charge ranging from 10 to $45 \mathrm{~g} \mathrm{Na}_{2} \mathrm{O}(100 \mathrm{~g} \mathrm{odw})^{-1}$, enabled to follow the alkali concentration profiles in the free and entrapped liquors. From the 41 cooking experiments available, 22 were chosen for solving this parameter estimation problem, while the remaining 19 were left for model validation. Therefore, a total of 132 experimental data points were employed to obtain optimal parameter estimates. Eqs. (9)-(18) were solved using the ODRPACK package [22] with the ordinary least squares criterion. Re-parameterization was performed on $k_{\mathrm{D}}$ and $E_{\mathrm{a}}$ being the estimated parameters $\beta_{1}=\ln \left(k_{\mathrm{D}}\right)-E_{\mathrm{a}} / 300 R$ and $\beta_{2}=$ $E_{\mathrm{a}} / 300 R$. The parameters for the initial additional consumption term $\left(k_{\text {in }}, a, b\right)$ were also estimated and it was also necessary to re-parameterize the coefficient $k_{\text {in }}$ using $\beta_{3}=k_{\text {in }} \times 10^{5}$.

The values of the optimal parameter estimates, as well as the corresponding standard deviations, are shown in Table 2. As can be seen by the standard deviations, the estimates for all parameters are characterized by very narrow confidence intervals, revealing a high level of statistical significance. The parity plot in Fig. 3 compares predicted values against experimental data for the alkali concentration in the free liquid for both model and validation points, in a total of 246 experimental data points. The statistical characterization of the residuals between predicted and experimental values is illustrated in Fig. 4, where one can see their Gaussian nature and the small variance of their distribution.

Fig. 5 shows model predictions against experimental data for two of the experiments used for parameter estimation, at the alkali charge of $15 \mathrm{~g} \mathrm{Na}_{2} \mathrm{O}(100 \mathrm{~g} \mathrm{odw})^{-1}$, i.e., at an initial concentration of alkali in the free liquid of $21 \mathrm{~g} \mathrm{Na}_{2} \mathrm{O} / \mathrm{L}$. The model predictions are very good, with an $R^{2}$ of 0.995 . This is true even for low pulping temperatures such as $80^{\circ} \mathrm{C}$. The initial fast reaction described by Eq. (17) allows predicting the fast decrease in the concentration of alkali registered in the free liquid in the first minutes of all pulping experiments, thus avoiding the overestimation of entrapped alkali concentration. These same conclusions can be drawn for the cooking experiments kept for model validation as can be seen in Fig. 6, which shows the model prediction and the experimental data for experiments at cooking temperatures of 140 and $165^{\circ} \mathrm{C}$. To be noticed that, although

Table 2

Optimal parameter estimates for the mass transfer model

\begin{tabular}{lclll}
\hline $\begin{array}{l}\text { Estimated } \\
\text { parameter }\end{array}$ & $\begin{array}{l}\text { Parameter } \\
\text { value }\end{array}$ & $\begin{array}{l}\text { Standard } \\
\text { deviation }\end{array}$ & $\begin{array}{l}\text { Model } \\
\text { parameter }\end{array}$ & $\begin{array}{l}\text { Parameter } \\
\text { value }\end{array}$ \\
\hline$\beta_{1}$ & -24.5 & 0.14 & $k_{\mathrm{D}}$ & $9.00 \times 10^{-8}$ \\
$\beta_{2}$ & 8.30 & 0.48 & $E_{\mathrm{a}}$ & $20.7 \times 10^{3}$ \\
$\beta_{3}$ & 5.64 & 1.36 & $k_{\mathrm{S}}$ & $5.64 \times 10^{-5}$ \\
$a$ & -3.79 & 0.32 & & \\
$b$ & 0.928 & 0.013 & & \\
\hline
\end{tabular}




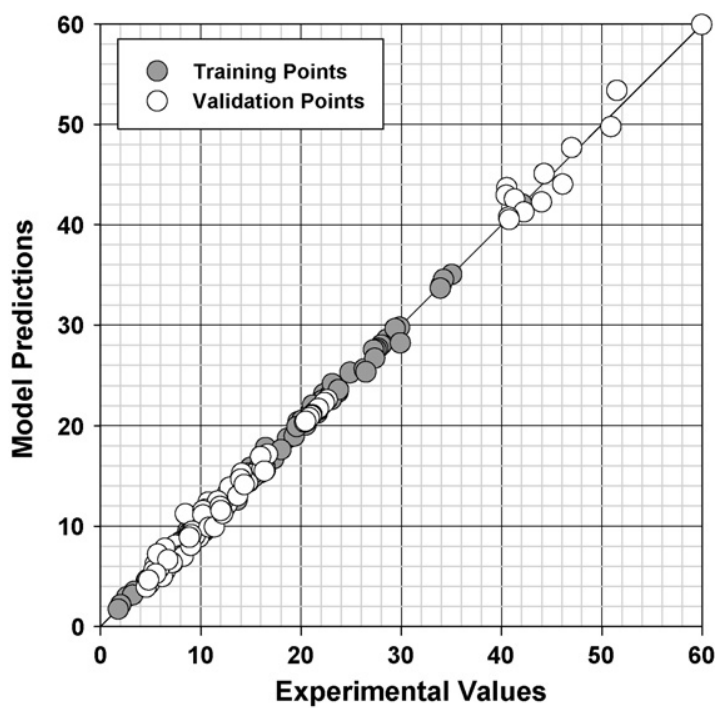

Fig. 3. Model predictions against experimental values for the effective alkali concentration in the free liquid (132 model points, in grey and 114 validation points, in white).

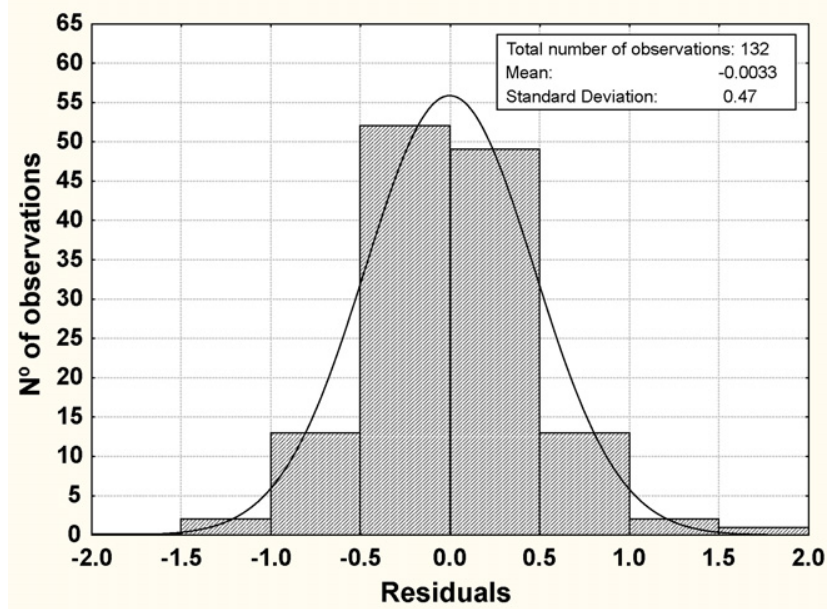

Fig. 4. Histogram of residuals.

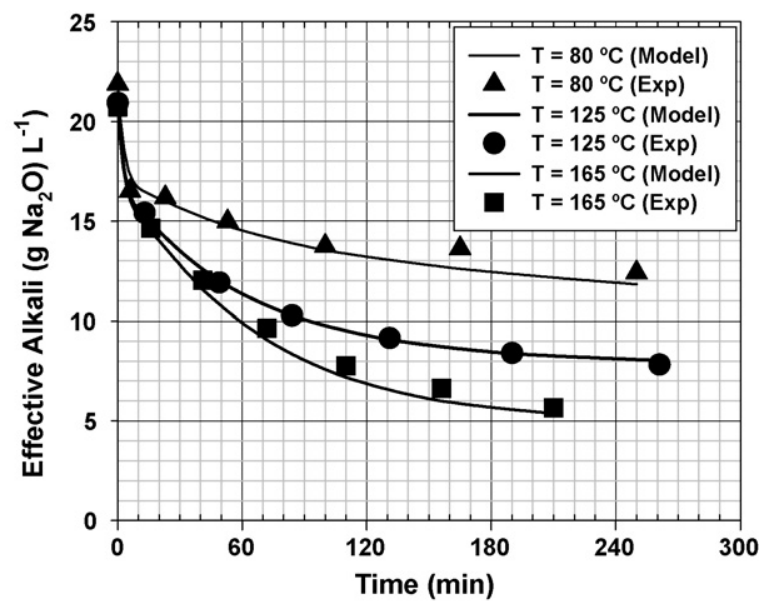

Fig. 5. Model predictions and experimental values for the concentration of effective alkali in the free liquor for three cooking experiments at different target temperatures $\left(\mathrm{EAC}=15 \mathrm{~g} \mathrm{Na}_{2} \mathrm{O}(100 \mathrm{~g} \mathrm{odw})^{-1}, S=30 \%\right)$.

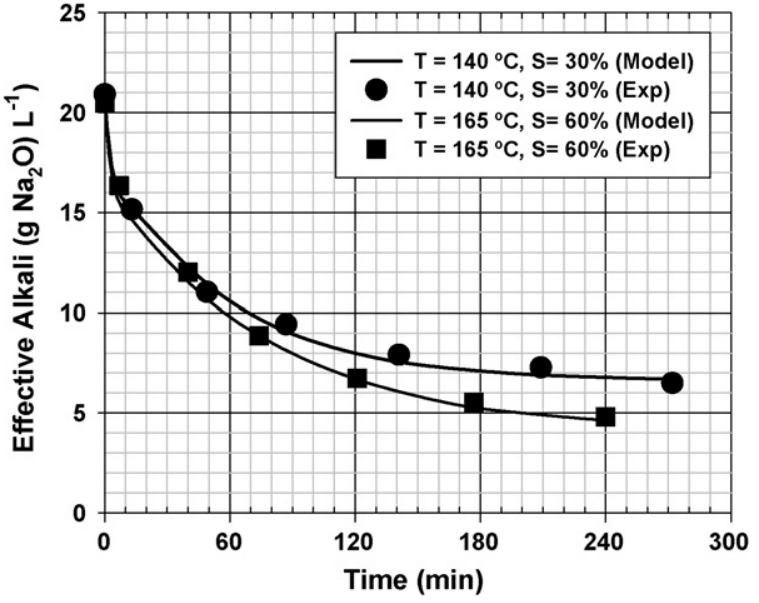

Fig. 6. Model predictions and experimental values for the concentration of effective alkali in the free liquor for two cooking experiments used for model validation at different target temperatures and sulphidities $(\mathrm{EAC}=15 \mathrm{~g}$ $\left.\mathrm{Na}_{2} \mathrm{O}(100 \mathrm{~g} \text { odw })^{-1}\right)$.

sulphidity has not been used as a parameter in model development, the model predictions are good even when sulphidity was set to $60 \%$ as illustrated in Fig. 6.

As shown in Table 2, the value of the activation energy for diffusion calculated with this lumped model is very similar to those reported by McKibbins [2] $\left(E_{\mathrm{a}}=20.4 \mathrm{~kJ} \mathrm{~mol}^{-1}\right)$, Talton and Cornell [3] $\left(E_{\mathrm{a}}=22.3 \mathrm{~kJ} \mathrm{~mol}^{-1}\right)$ and Robertsén and Lönnberg [4] $\left(E_{\mathrm{a}}=23.7 \mathrm{~kJ} \mathrm{~mol}^{-1}\right)$, thus supporting the reliability of the model.

One important feature that distinguishes the present study from the others above mentioned is that the estimates of the mass transfer parameters are not influenced by the chemical reactions taking place inside the chips, due to the use of experimental data on alkali concentration in the entrapped liquor. Moreover, this model enables to measure the external resistance to mass transfer and its contribution to the overall rate of the mass transfer process, which was unknown and neglected up to now. In the cooks performed at temperatures in the industrial range, this contribution may not be simply neglected, as shown

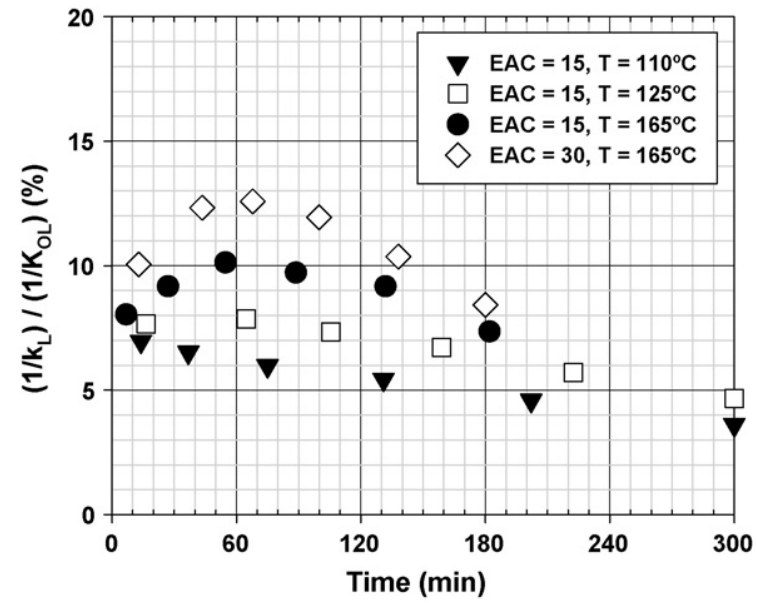

Fig. 7. Ratio of external resistance over the total resistance to mass transfer at different cooking conditions. 
in Fig. 7, where the ratio of the external resistance over the total mass transfer resistance is plotted against time for three different pulping temperatures. As it can be seen, the relevance of the external resistance increases with cooking temperature in a non-linear way and it smoothes away during the cook. The non-constancy on the contribution of the external mass transfer resistance is particularly noticed at $165^{\circ} \mathrm{C}$, a typical industrial pulping temperature, and is accentuated at the alkali charge of $30 \mathrm{~g} \mathrm{Na}_{2} \mathrm{O}\left(100 \mathrm{~g} \mathrm{odw}^{-1}\right.$ where it can go up to $13 \%$ of the global alkali mass transfer resistance. It should be noticed that the estimated external diffusion coefficient is valid on the range of operating conditions used. The results suggest that the external resistance to mass transfer should not be overlooked and can be a subject for new studies in this field.

\section{Conclusions}

In this study a model for the mass transfer of effective alkali in kraft pulping of wood has been developed, based on a lumped parameter approximation and on experimental data for the alkali concentrations measured in both the free and the entrapped liquors. The fast consumption of effective alkali that occurs at the beginning of the cook was well described by relating it to a minimum "critical" alkali concentration and the corresponding term was added to the mass balance of the alkali in the free liquor. The value obtained for the activation energy for diffusion of alkali inside the chips $\left(20.7 \mathrm{~kJ} \mathrm{~mol}^{-1}\right)$ is consistent with those reported in the literature. Moreover, this model has shown to be able to predict the contribution of both internal and external resistances to the overall rate of mass transfer, in a range of pulping temperatures from 80 to $165^{\circ} \mathrm{C}$. Although in previous studies the external resistance in the film has been neglected, the work here reported shows its significant contribution to the overall mass transfer coefficient at normal industrial cooking conditions. In addition, it is shown that this influence increases with the temperature and the alkali charge used in the cook. The proposed mass transfer model has been experimentally validated and can be used in conjunction with a chemical reaction model based on realistic reactant concentrations inside the chip porous structure. This is a critical step in developing a trustworthy heterogeneous kraft pulping model and therefore to better optimization studies of industrial pulping reactors.

\section{Acknowledgements}

Financial support granted by Ministry of Science and Technology under Project Praxis 3/3.2/PAPEL/2327/95 is gratefully acknowledged. J.P. Simão is also grateful to Ministry of Science and Technology for his scholarship PRAXIS_XXI/BD/22236/99. The authors are also grateful to RAIZ, Instituto de Investigação da Floresta e do Papel, for its financial and laboratory support and for supplying all the wood used in this project.

\section{References}

[1] N.C.P. Fernandes, J.A.A.M. Castro, Steady-state simulation of a continuous moving bed reactor in the pulp and paper industry, Chem. Eng. Sci. 55 (18) (2000) 3729-3738.

[2] S.W. McKibbins, Application of diffusion theory to the washing of kraft cooked wood chips, Tappi J. 43 (10) (1960) 801-805.

[3] J.H. Talton Jr., R.H. Cornell, Diffusion of sodium hydroxide in wood at high $\mathrm{pH}$ as a function of temperature and the extent of pulping, Tappi J. 70 (1) (1987) 115-118.

[4] L. Robertsén, B. Lönnberg, Diffusion in wood. Part 2. The effects of concentration and temperature, Paperi ja Puu 73 (7) (1991) 635-639.

[5] T. Hultholm, L. Robertsén, B. Lönnberg, A. Kettunen, K. Henricson, Impregnation in alkaline pulping, in: Proceedings of the Tappi Pulping Conference, 1997, pp. 897-902.

[6] D.B. Tyler, L.L. Edwards, Predicting rejects from kraft cooking of overthick chips - a model incorporating caustic diffusion with delignification kinetics, Svensk Papperstidn. 85 (18) (1982) 180-184.

[7] R.R. Gustafson, C.A. Sleicher, W.T. McKean, B.A. Finlayson, Theoretical model of the kraft pulping process, Ind. Eng. Chem. Process Des. Dev. 22 (1) (1983) 87-96.

[8] S. Mirams, K.L. Nguyen, A predictive model of eucalypt kraft pulping, Proc. Appita (1994) 187-194.

[9] N. Agarwal, R. Gustafson, S. Arasakesari, Modeling the effect of chip size in kraft pulping, Paperi ja Puu-Paper and Timber 76 (6-7) (1994) 410-416.

[10] A.P.V. Egas, J.P.F. Simão, I.M.M. Costa, S.C.P. Francisco, J.A.A.M. Castro, Experimental methodology for heterogeneous studies in pulping of wood, Ind. Eng. Chem. Res. 41 (10) (2002) 25292534.

[11] K.M.F. Kazi, H. Gauvin, P. Joliez, E. Chornet, A diffusion model for the impregnation of lignocellulosic materiais, Tappi J. 80 (11) (1997) 209-219.

[12] A. Rosen, Adsorption of sodium ions on kraft pulp fibers during washing, Tappi 58 (9) (1975) 156-161.

[13] G. Eriksson, U. Grén, Pulp washing: sorption equilibria of metal ions on kraft pulps, Nordic Pulp Paper Res. J. 11 (3) (1966) 164-170.

[14] J.P.F. Simão, A.P.V. Egas, C.M.S.G. Baptista, M.G. Carvalho, J.A.A.M. Castro, Evolution of methylglucuronic and hexenuronic acid contents of eucalyptus globulus pulp during kraft delignification, Ind. Eng. Chem. Res. 44 (9) (2005) 2990-2996.

[15] J.P.F. Simão, A.P.V. Egas, C.M.S.G. Baptista, M.G. Carvalho, Heterogeneous kinetic model for the methylglucuronic and hexenuronic acids reactions during kraft pulping of Eucalyptus globulus, Ind. Eng. Chem. Res. 44 (9) (2005) 2997-3002.

[16] A. Romanenko, J.A.A.M. Castro, An RT-Linux based control system of a pilot plant for reaction kinetics and process control studies, Comp. Chem. Eng. 24 (2000) 1063-1068.

[17] L. Olm, G. Tistad, Kinetics of the initial stage of kraft pulping, Svensk Papperstidn. $27 \quad$ (15) (1979) 458464.

[18] P.N. Dwidevi, S.N. Upadhyay, Particle-fluid mass transfer in fixed and fluidized beds, Ind. Eng. Chem. Process Des. Dev. 16 (2) (1977) 157-165.

[19] I.M.R. Gonçalves, L.Q. Lobo, Estudo preliminar da reologia do licor negro de eucalipto, Silva Lusitana 1 (2) (1993) 131-140 (article in Portuguese)

[20] M.A. Burazin, A Dynamical Model of Kraft Antraquinone Pulping, Ph.D. Thesis, Lawrence University, 1986.

[21] D.R. Lide (Ed.), Ionic conductivity and diffusion at infinite dilution, in: CRC Handbook of Chemistry and Physics, CRC Press, Boca Raton, FL, 2005 (Internet Version, <http://www.hbcpnetbase.com>).

[22] P.T. Boggs, R.H. Byrd, J.E. Rogers, R.B. Schnabel, User's Reference Guide for ODRPACK version 2. 01-Software for Weighted Orthogonal Distance Regression, U.S. Government Printing Office, 1992. 